\title{
Upaya Peningkatan Perkembangan Bahasa melalui Metode Role Play bagi Anak Tunagrahita di SLBN Pembina Mataram
}

\author{
Eka Adithia Pratiwi ${ }^{1}$, Misroh Mulianingsih ${ }^{2}$, Fitri Romadonika ${ }^{3}$, Supriyadi ${ }^{4}$ \\ pratiwiekaadithia@gmail.com ${ }^{1}$, misroh.yarsi@gmail.com², romadonika.fitri@yahoo.com³ \\ supriyadi.stikesyarsi@gmail.com ${ }^{4}$ \\ 1,2,3,4 STIKES YARSI Mataram
}

Article History:
Received: 13-06-2021
Revised: $21-06-2021$
Accepted: $22-07-2021$

Keywords: Mental retardation, role play, language development

\begin{abstract}
Mentally retarded children are children who have intelligence below the average that occurs during development and have obstacles in adaptive assessment. The language development of mentally retarded children is basically lower than that of children in general, most children cannot achieve perfect language skills, language development is very lagging compared to children in general, even at the same Mental Age. Talking activities are very important for mild type mentally retarded students, because the potential for mild-type mentally retarded students to speak can still be maximally optimized, by speaking, students can communicate formally with the teacher during activities teaching and learning is carried out in the classroom. The goal is to improve language skills in mentally retarded children. The method of implementing activities using Role Play method. The results before the intervention of 5 samples of speech ability in the moderate category of 3 people (83.3\%), and in the poor category as many as 2 people (16.7\%), after getting the intervention speaking ability in the good category 2 people (40\%), enough 3 people (60\%). So it can be concluded that there is an increase in language skills in children with mild mental retardation
\end{abstract}

\section{Pendahuluan}

Tunagrahita merupakan salah satu jenis anak berkebutuhan khusus yang memiliki keterbatasan fungsi intelektual dan adaptasi. Keterbatasan fungsi intelektual ini menyebabkan anak tunagrahita menjadi tidak matang dalam merespon lingkungan, memiliki kemampuan akademik di bawah rata-rata dan juga dalam aspek psikologi, bahasa dan sosial menunjukkan keterbatasan (Suharmini, 2007: 69). Anak tunagrahita adalah anak yang memiliki kecerdasan di bawah rata-rata yang terjadi pada saat masa perkembangan dan memiliki hambatan dalam penilaian adaptif. Secara harafiah kata tuna adalah merugi, sedangkan grahita adalah pikiran, dengan demikian ciri utama dari anak tunagrahita adalah lemah dalam berpikir atau bernalar, kurangnya kemampuan belajar dan adaptasi sosial berada di bawah rata-rata (Abdulrachman, 1994:19). Untuk mengatasi hambatan-hambatan tersebut, anak tunagrahita diberikan cara pelayanan pendidikan yang berbeda dengan anak normal dan harus disesuaikan dengan taraf kelainannya. American Association On Mental Deliciency (AAMD) dalam Mumpuniarti (2007:13) mengatakan klasifikasi tunagrahita 
adalah tunagrahita ringan dengan IQ berkisar 50-70, tunagrahita sedang dengan IQ berkisar 30-50 dan tunagrahita berat dan sangat berat dengan IQ berkisar $<30$.

Ketiga jenis tunagrahita tersebut, anak tunagrahita ringan adalah anak yang mengalami hambatan dalam berbagai aspek, diantaranya dalam kemampuan mental, bahasa, motorik, emosi dan sosial. Menurut Edgar Dole dalam Efendi (2006 : 89) mengatakan bahwa seseorang dikatakan tunagrahita jika (1) secara sosial tidak cakap, (2) secara mental di bawah anak normal sebayanya, (3) Kecerdasan terhambat sejak lahir atau pada usia muda dan (4) kematangannya terhambat.

Anak tunagrahita tipe ringan memang mempunyai kesulitan melakukan persepsi verbal dan non-verbal sehingga berakibatkan hal-hal yang sederhana seringkali sulit dicerna. Tetapi penguasaan bahasa yang dimiliki anak tunagrahita ringan masih dapat dioptimalkan. Sekalipun demikian dari seluruh anak tunagrahita, anak tunagrahita tipe ringan merupakan tipe individu yang lancar berbicara tetapi perbendaharaan kata yang dimiliki masih kurang serta mengalami kesulitan berpikir abstrak. Anak tunagrahita tipe ringan dengan perbendaharaan kata yang kurang masih dapat mengikuti pelajaran akademik baik di sekolah biasa maupun di sekolah khusus dengan layanan dan tindakan khusus.

Anak tunagrahita memiliki potensi dalam belajar dan erat kaitannya dengan beratringan tunagrahita. Kebutuhan khusus yang dimaksud adalah kebutuhan layanan pengajaran. Dapat disadari bahwa keterbatasan kemampuan berpikir mereka sudah tentu mengalami kesulitan belajar dalam bidang akademik salah satunya adalah membaca dan mengenal huruf serta angka.

Anak tunagrahita tipe ringan memang mempunyai kesulitan melakukan persepsi verbal dan non-verbal sehingga berakibatkan hal-hal yang sederhana seringkali sulit dicerna. Tetapi penguasaan bahasa yang dimiliki anak tunagrahita ringan masih dapat dioptimalkan. Sekalipun demikian dari seluruh anak tunagrahita, anak tunagrahita tipe ringan merupakan tipe individu yang lancar berbicara tetapi perbendaharaan kata yang dimiliki masih kurang serta mengalami kesulitan berpikir abstrak. Anak tunagrahita tipe ringan dengan perbendaharaan kata yang kurang masih dapat mengikuti pelajaran akademik baik di sekolah biasa maupun di sekolah khusus dengan layanan dan tindakan khusus.

Menurut Tarigan (2008:16) berbicara adalah kemampuan mengucapkan bunyi-bunyi artikulasi atau kata-kata untuk mengekspresikan, menyatakan atau menyampaikan pikiran, gagasan, dan perasaan. Kegiatan berbicara sangat penting bagi siswa tunagrahita tipe ringan, karena potensi siswa tunagrahita tipe ringan untuk berbicara masih dapat dioptimalkan secara maksimal, dengan berbicara, siswa dapat melakukan komunikasi secara formal dengan guru pada saat kegiatan belajar mengajar yang dilaksanakan di dalam 
kelas, sehingga antara siswa dan guru menjadi saling mengerti maksud dan tujuan dari pembicaraan yang sedang berlangsung.

Salah satu tindakan yang dapat dilakukan untuk meningkatkan kemampuan bahasa anak RM adalah dengan menggunakan metode Role Play. Metode role playing dapat mempermudah siswa dalam mempelajari kemampuan berbicara karena metode role playing menuntut keaktifan siswa untuk selalu terlibat dalam pelaksanaannya. Siswa diberikan peranan untuk dapat mendramatisasikan tingkah laku, atau ungkapan gerak gerik wajah seseorang dalam hubungan sosial antar manusia, selain itu siswa juga dapat memainkan peran dalam dramatisasi masalah sosial.

Dalam penerapan metode role playing ini memungkinkan siswa tunagrahita tipe ringan untuk dapat belajar dan berlatih dalam suasana yang nyaman, menyenangkan serta menarik minat siswa untuk lebih fokus belajar tanpa meninggalkan tujuan pembelajaran, sehingga siswa tidak merasa jenuh dalam mengikuti proses pembelajaran dan tujuan pembelajaran yang telah ditentukan dapat tercapai. Berdasarkan hasil penelitian Raya (2015) didapatkan hasil bahwa penggunaan metode role playing dapat meningkatkan kemampuan berbicara pada siswa tunagrahita tipe ringan kelas 2 SDLB Negeri 1 Bantul dengan menggunakan cerita pendek. Berdasarkan hasil wawancara dari 5 siswa 2 siswa dapat menjawab gambar yang ditanyakan, 2 orang menjawab tapi tidak jelas, dan 1 orang tidak menjawab.

\section{Metode}

Lokasi kegiatan pengabdian kepada masyarakat ini dilakukan di SLBN Pembina Mataram dimana partisipan adalah siswa/siswi dengan RM tingkat ringan. Metode yang digunakan dengan Role Play menggunakan cerita pendek tentang Kejujuran dalam kehidupan seharihari. Kegiatan ini dilaksanakan dalam 3 tahap siklus, dimana pada kegiatan awal dilakukan tes kemampuan berbicara, kemudian tahap I anak RM berperan sebagai penjual dan pembeli dan tahap ke II berperan sebagai penemu dompet.

1) Tahap awal melakukan tes kemampuan bicara anak RM

2) Tahap 1

a. Membagi siswa menjadi 2 kelompok, masing-masing kelompok terdiri dari 2 siswa dan menentukan peran sebagai penjual dan pembeli,

b. Setiap kelompok RM memiliki 2 orang Fasilitator yang akan membantu dalam kegiatan Role Play untuk menceritakan cerita pendek dan sekaligus mempraktikan kegiatan yang sudah di buat sehingga anak RM dapat lebih mudah untuk memahami isi cerita yang akan di mainkan. Pembacaan ini dapat dilakukan beberapa kali hingga 


\section{ADMA}

Jurnal Pengabdian dan Pemberdayaan Masyarakat
Tahun, Vol.2, No.1, pp.117-124

Doi: $10.30812 / a d m a . v 2 i 1.1264$

para siswa sudah memiliki gambaran tentang konsep bermain peran dan cerita yang akan diperankan selama 30 menit,

c. Siswa memulai sesi pemeranan dari masing-masing peran yang dilakukan sesuai dengan skenario yang telah disusun sebelumnya,

d. Melakukan review dari kegiatan percakapan yang menggunakan metode role play yang telah dilakukan, dan melakukan evaluasi.

3) Tahap 2

a. Membagi siswa menjadi 2 kelompok dan didampingi oleh 2 orang fasilitator dari mahasiswa STIKES YARSI Mataram,

b. Fasilitator menceritakan ilustrasi cerita kepada siswa/siswi mengenai tindakan yang dilakukan ketika menemukan dompet di jalan secara berulang-ulang sampai siswa lancar menyampaikan dialog ceritanya,

c. Memberikan pertanyaan kepada siswa mengenai tindakan yang seharusnya dilakukan ketika menemukan dompet di jalan dan jawab disertai dengan pendapat masing-masing siswa,

d. Siswa diminta melakukan simulasi yang dilanjutkan dengan pemeranan secara mandiri ketika menemukan dompet yang terjatuh di jalan,

e. Melakukan review kegiatan yang dilakukan dengan cara siswa diminta menceritakan kembali kegiatan yang telah dilakukan kemudian mengungkapkan pendapat mengenai pembelajaran yang telah dilaksanakan,

f. Melakukan evaluasi.

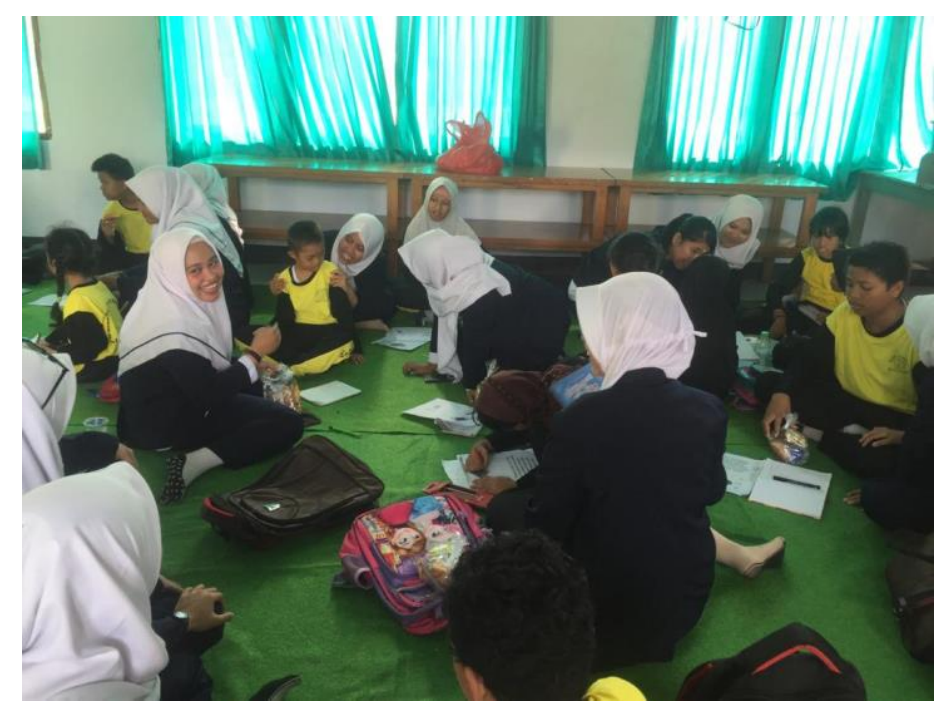

Gambar 1. Pembagian kelompok dan fasilitator membacakan alur cerita dalam skenario 


\section{Pembahasan}

Program pengabdian kepada masyarakat diikuti oleh siswa/siswi RM SLBN Pembina Mataram. Program ini diikuti secara antusias dan terlihat keceriaan diantara siswa/siswi tersebut. Peserta mendapatkan penjelasan tentang kegiatan yang akan dilaksanakan oleh Dosen dan 10 orang mahasiswa/mahasiswi dari STIKES YARSI Mataram.

Indikator keberhasilan kegiatan pengabdian kepada masyarakat berdasarkan pengamatan langsung selama kegiatan berlangsung adalah sebagai berikut :

Tabel 1. Kemampuan berbicara siswa tunagrahita ringan

\begin{tabular}{c|c|c|l|c|l|c|c}
\hline No & Peserta & \multicolumn{2}{|c|}{ Awal } & \multicolumn{2}{c|}{ Tahap I } & \multicolumn{2}{c}{ Tahap II } \\
\cline { 3 - 7 } & $\begin{array}{c}\text { Skor } \\
\text { yang di } \\
\text { peroleh }\end{array}$ & Kategori & $\begin{array}{c}\text { Skor } \\
\text { yang di } \\
\text { peroleh }\end{array}$ & Kategori & $\begin{array}{c}\text { Skor yang } \\
\text { di peroleh }\end{array}$ & Kategori \\
\hline 1 & P.1 & 7 & Kurang & 9 & Kurang & 12 & Cukup \\
\hline 2 & P.2 & 13 & Cukup & 14 & Cukup & 16 & Baik \\
\hline 3 & P.3 & 12 & Cukup & 13 & Cukup & 15 & Baik \\
\hline 4 & P.4 & 9 & Kurang & 10 & Cukup & 13 & Cukup \\
\hline 5 & P.5 & 11 & Kurang & 12 & Cukup & 14 & Cukup \\
\hline & $\begin{array}{c}\text { Rata- } \\
\text { rata }\end{array}$ & 10,4 & Kurang & 11.6 & Cukup & 14 & Cukup \\
\hline
\end{tabular}

Berdasarkan hasil analisis pada tabel 1 didapatkan hasil bahwa keterampilan berbicara siswa tunagrahita tipe ringan mengalami peningkatan dibandingkan pada saat tes kemampuan awal. Hal tersebut dapat dilihat pada peserta 1 yang pada saat tes kemampuan awal mendapat skor 7 meningkat menjadi 9 pada saat tes setelah tindakan tahap 1, dan meningkat menjadi skor 12 setelah tindakan tahap II, begitu juga dengan peserta lainnya. Peningkatan keterampilan berbicara siswa tunagrahita tipe ringan ditunjukkan dengan peningkatan skor rata-rata kelas dari 10,4 (dipersentase menjadi 52\%) pada tes kemampuan awal menjadi 11.6 (58\%) pada tes pasca tindakan tahap I, dan menjadi 14 (70\%) pada tes tahap II. Hal ini menunjukkan bahwa seluruh siswa telah memenuhi kriteria keberhasilan pada skor 13 atau sebesar $65 \%$.

Adanya peningkatan kemampuan berbicara menggunakan bahasa Indonesia pada anak tunagrahita tipe ringan tersebut disebabkan bimbingan belajar melalui role playing dapat membuat seluruh siswa berpartisipasi, mempunyai kesempatan untuk memajukan kemampuannya dalam bekerja sama. Pembelajaran dengan role playing merupakan bimbingan belajar melalui permainan, sehingga mudah dan dapat digunakan dalam situasi dan waktu yang berbeda. Hal ini sesuai dengan pendapat Martinis Yamin (2006: 149) yang menyatakan bahwa metode role playing dapat melibatkan seluruh siswa dalam kegiatan pembelajaran serta permainan memberikan pengalaman belajar yang menarik dan menyenangkan bagi siswa. Selain itu, sesuai dengan pendapat Oemar Hamalik (2008: 214) 
bahwa dalam pembelajaran dengan metode role playing siswa dapat bertindak dan mengekspresikan perasaan dan pendapat, siswa dapat mendiskusikan suatu topik, siswa dapat mengidentifikasi situasii dalam dunia nyata.

Metode role playing membuat para siswa tunagrahita ringan mengalami secara langsung kegiatan berbicara yang membuat mereka memiliki pengalaman nyata tentang berbicara dengan kata-kata yang tepat sehingga membantu mereka merekam atau mengingat katakata tersebut. metode role playing dapat mengkondisikan siswa tunagrahita tipe ringan untuk memiliki dan meningkatkan keberanian serta kemandirian dalam belajar. Ketika bermain peran, para siswa belajar untuk menguasai kalimat atau kata yang menjadi tanggung jawab peran mereka. Dengan demikian, secara mandiri siswa berusaha untuk berbicara, meningkatkan kemampuan berbicaranya dengan pelafalan kata yang diucapkan jelas, intonasi suara sudah jelas dan penekanan pada kalimat yang diucapkan baik.

Mengingat anak tunagrahita ringan termasuk kelompok tunagrahita mampu didik, maka metode role playing sehingga dapat melatih dan meningkatkan kemampuan berbicara siswa tungrahita ringan. Bagi siswa tungrahita ringan, sekalipun dapat mengulang kalimat, siswa belum tentu mampu memahami isi percakapan yang dilakukan. Karena itu, masih dibutuhkan penjelasan dan pengulangan di setiap kalimat percakapan. Dalam memerankan tokoh, siswa masih membutuhkan pendampingan dan pengulangan berkali-kali dari guru.

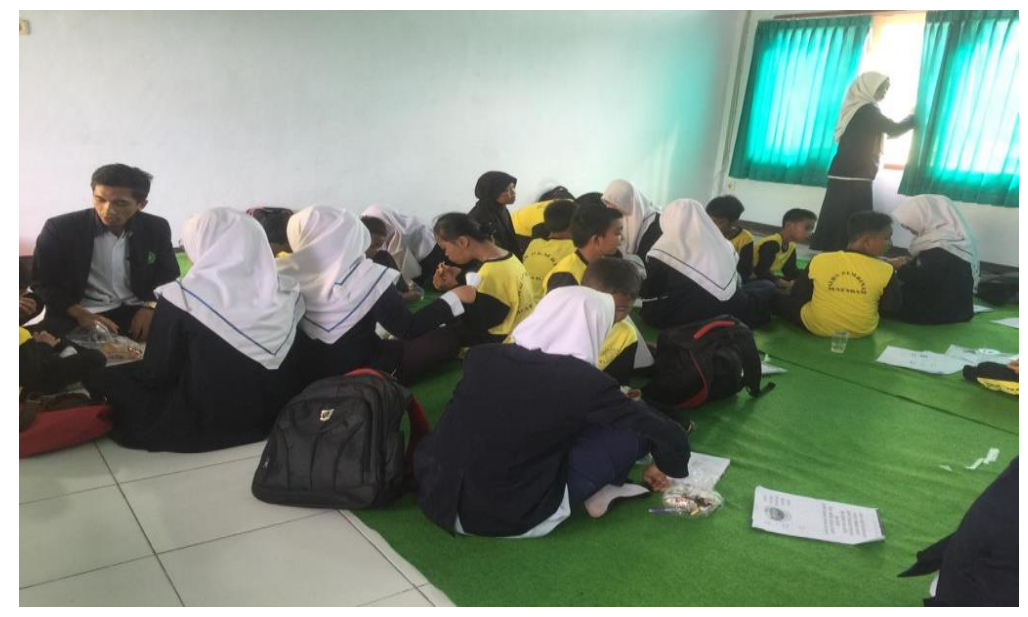

Gambar 2 : Foto dokumentasi pengabdian

\section{Kesimpulan}

Metode role play dapat meningkatkan kemampuan bicara anak tunagrahita ringan hal tersebut dapat dilihat dari adanya peningkatan hasil skor rata-rata kemampuan bicara anak pada saat awal tes dilakukan yaitu 10,4 kategori kurang (52\%), kemudian meningkat menjadi 11.6 kategori kurang (58\%) pada tindakan tahap 1 dan meningkat menjadi 14 kategori cukup (70\%). 
Guru sebaiknya terus melaksanakan dan mengembangkan metode belajar melalui metode role playing dengan cara yang menyenangkan, selalu mengulang-ulang instruksi agar dipahami siswa serta dengan mengambil tema sekita kehidupan sehari-haris yang dialami siswa agar membantu siswa tunagrahita ringan menguasai kemampuan berbicara khususnya untuk berkomunikasi tentang hal yang diperlukan sehari-hari.

Kesediaan guru untuk terus mendampingi, membimbing dan berulang ulang melatih siswa untuk mengucapkan percakapan dengan temannya dalam satu dialog yang terstruktur dapat membantu siswa menguasai dan meningkatkan kemampuan berbicaranya. Bagi sekolah metode role play ini dapat dijadikan salah satu metode pembelajaran yang dapat digunakan oleh guru.

\section{Ucapan Terimakasih}

Ucapan terima kasih disampaikan kepada semua pihak yang telah ikut andil sehingga terlaksananya kegiatan Pengabdian Kepada Masayarakat ini.

\section{Daftar Pustaka}

Efendi, M. (2006). Psikopedagogik Anak Berkelainan. Jakarta : Bumi Aksara.

Hamalik, O. 2008. Proses Belajar Mengajar. Jakarta: Bumi Aksara.

Mumpuniarti. (2007). Pembelajaran Akademik Bagi Tunagrahita. Yogyakarta: FIP UNY.

Raya, F. P. (2015). Peningkatan Kemampuan Berbicara Menggunakan Bahasa Indonesia Dengan Metode Role Playing Bagi Anak Tunagrahita Tipe Ringan Kelas 2 Sdlb Di SIb Negeri 1 Bantul. UNY

Tarigan, H. G. (2008). Membaca Sebagai Suatu Keterampilan Berbahasa. Bandung: $\quad$ Angkasa

Suharmini, T. (2009). Psikologi Anak Berkebutuhan Khusus. Yogyakarta : Kanwa.

Yamin, M. (2006). Strategi Pembelajaran Berbasis Kompetensi. Jakarta : Gaung Persada. 
